\title{
Visualization of Iron-Binding Micelles in Acidic Recombinant Biomineralization Protein, MamC
}

\author{
Sanjay Kashyap, ${ }^{1}$ Taylor Woehl, ${ }^{1}$ Carmen Valverde-Tercedor, ${ }^{2}$ Miguel Sánchez-Quesada, ${ }^{2}$ \\ Concepción Jiménez López, ${ }^{2}$ and Tanya Prozorov ${ }^{1}$ \\ ${ }^{1}$ Ames Laboratory, U.S. Department of Energy, Ames, IA 50011, USA \\ ${ }^{2}$ Department of Microbiology, University of Granada, Campus de Fuentenueva s/n, 18071 Granada, Spain \\ Correspondence should be addressed to Tanya Prozorov; tprozoro@ameslab.gov
}

Received 13 January 2014; Revised 1 March 2014; Accepted 2 March 2014; Published 7 April 2014

Academic Editor: Hao Bai

Copyright (C) 2014 Sanjay Kashyap et al. This is an open access article distributed under the Creative Commons Attribution License, which permits unrestricted use, distribution, and reproduction in any medium, provided the original work is properly cited.

\begin{abstract}
Biological macromolecules are utilized in low-temperature synthetic methods to exert precise control over nanoparticle nucleation and placement. They enable low-temperature formation of a variety of functional nanostructured materials with properties often not achieved via conventional synthetic techniques. Here we report on the in situ visualization of a novel acidic bacterial recombinant protein, MamC, commonly present in the magnetosome membrane of several magnetotactic bacteria, including Magnetococcus marinus, strain MC-1. Our findings provide an insight into the self-assembly of MamC and point to formation of the extended protein surface, which is assumed to play an important role in the formation of biotemplated inorganic nanoparticles. The selforganization of MamC is compared to the behavior of another acidic recombinant iron-binding protein, Mms6.
\end{abstract}

\section{Introduction}

Biomimetics employs a variety of biological macromolecules such as matrices, scaffolds, and templating agents, with the protein-driven nucleation playing an important role in the formation and growth of templated inorganic nanocrystals [1-12]. Bioinspired synthesis of uniform magnetic functional materials is a subject of intense research worldwide, owing to the interest in their functionality and performance in many fields of technology, from high-density magnetic data recording to catalysis and cancer therapy [13-23]. The fulllength recombinant acidic bacterial iron-binding protein, hisMms6, was shown to promote the shape-specific formation of the nanocrystals, and this bioinspired approach was later utilized for templated synthesis of more complex and highly magnetic cobalt ferrite nanocrystals $[13,17,21,23-$ $26]$. Formation of an extended protein surface was assumed to facilitate nucleation and growth of uniform nanocrystals $[15,17,22,27]$. Much less research has been done on MamC, a magnetosome protein present in Magnetospirillum magnetotacticum MS-1, $M$. gryphiswaldense MSR-1, M. magneticum AMB-1 magnetotactic vibrio MV-1, and Magnetococcus marinus MC-1 [28-31]. Similar to Mms6, MamC has a hydrophilic
C-terminus rich in amino acids containing hydroxyl and carboxyl groups; it also contains a hydrophobic $\mathrm{N}$-terminus. The acidic C-terminus is assumed to have an active role in magnetite biomineralization [32].

While obtaining X-ray quality crystals of novel proteins and solving their structure can take years $[33,34]$, the latest generation scanning transmission electron microscopes (STEM) allow visualization of the functionality and templating action of these biomacromolecules with sufficiently high resolution at the nanoscale [12, 20,35-53]. Moreover, use of fluid cell TEM holders allows examination of a variety of macromolecular complexes in their native, unaltered, fully hydrated state, providing a unique window into the high-resolution characterization of the dynamic phenomena taking place in biological structures in liquid [50,54-57].

Here we report on the in situ characterization of a novel bacterial recombinant acidic biomineralization protein, $\mathrm{MamC}$, and the binding of iron to the surface of this protein. Another bacterial recombinant iron-binding protein, Mms6, is used as a reference. Our results aid in understanding the protein self-assembly and the role it plays in the nucleation and growth of a biotemplated nanoparticle. Among the 

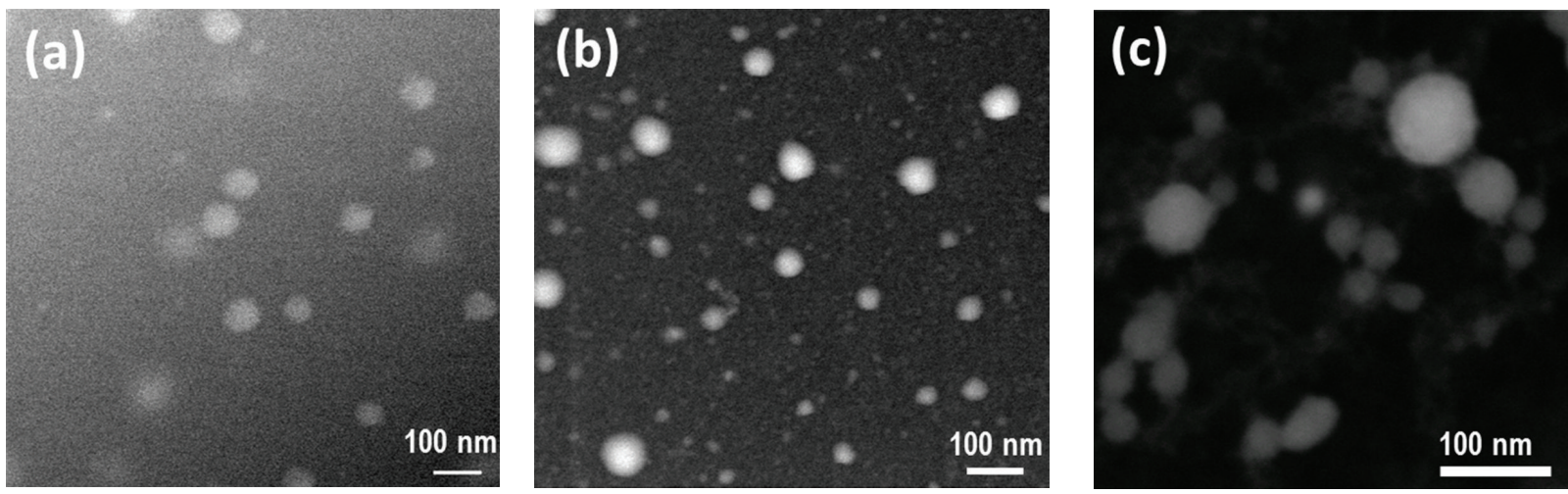

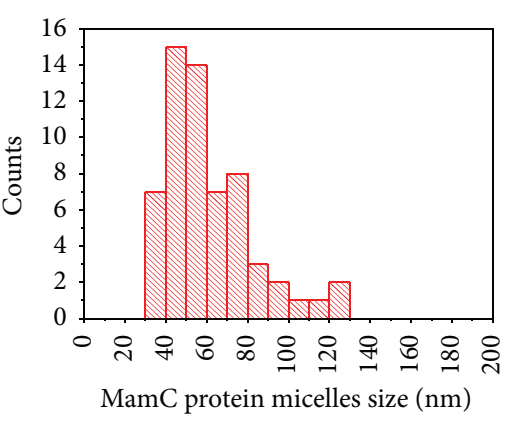

(a)

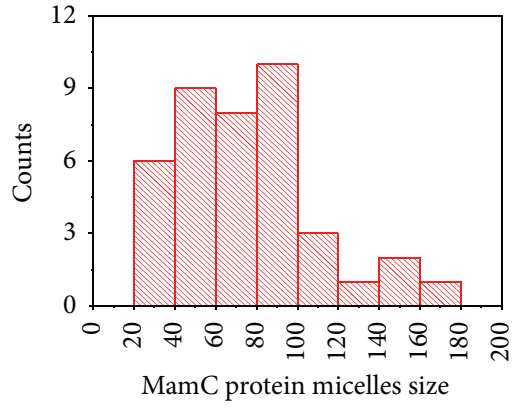

(b)

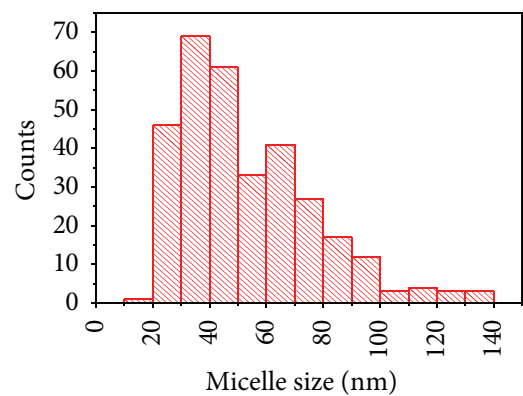

(c)

FIGURE 1: In situ HAADF-STEM images and size distribution of micelles of biomineralization recombinant proteins in liquid: (a) MamC before incubation and (b) after incubation with iron chloride; (c) Mms6 incubated with iron chloride, shown for comparison. Scale bars: $100 \mathrm{~nm}$.

several acidic membrane proteins associated with the magnetosome magnetite membrane of magnetotactic bacteria, Mms6 and MamC are believed to be the dominant proteins involved in magnetosome formation and growth $[24,29,58]$. Moreover, since MamC represents one of the most commonly present and abundant proteins, and it is believed to be involved in regulating the size of the magnetosome magnetite crystals, MamC could be used in the biomimetic synthesis of shape-specific magnetite nanocrystals [59].

\section{Results and Discussion}

Figure 1 shows in situ fluid cell HAADF images of MamC micelles in liquid and micelle size distribution obtained (a) before and (b) after overnight incubation with ferric chloride. The intensity of the HAADF-STEM images depends primarily on the atomic number, $Z$, and mass thickness of the specimen, thus providing chemical, compositional, and morphological information of the sample. The enhancement in the contrast of the iron-incubated micelles in Figure 1(b) was attributed to the surface localization of iron: due to iron's higher atomic number with respect to the surrounding organic material, it is easily detected with the HAADF detector. Here the positively charged ferrous ions appear to bind preferentially to the negatively charged protein micelles. In situ HAADF STEM provides a visual qualitative confirmation of surface iron binding. These findings are in good agreement with the zeta potential of MamC, $\zeta=-22.5 \pm 2 \mathrm{mV}$, which is indicative of a net negative surface charge, thus facilitating the binding of iron cations. Figure 1(c) shows iron-incubated micelles in Mms6 and their size distribution for comparison. Similar to the iron-incubated MamC micelles, the Mms6 micelle shows a relatively large HAADF signal compared to the background, due to the presence of iron.

The iron-incubated protein micelles appear to undergo further self-assembly and form an extended surface (Figures 2 and 4). Iron surface binding results in an increased surface concentration of iron ions with higher atomic number, rendering the micelle-bound ferrous iron highly visible in the HAADF image. The surface-localized iron binding leads to a local increase in the iron supersaturation at the surface of the protein micelles, enabling the biomimetic formation of biomimetic iron oxide nanocrystals external to the micelle core, with virtually no size restrictions. For example, magnetite nanocrystals synthesized in the presence of Mms6 exhibit, on average, the mean size of $30 \mathrm{~nm}$, while those synthesized in the presence of MamC have an average size of $80 \mathrm{~nm}[57,59,60]$. Such a scenario is drastically different from the case of the ferritin-templated nanocrystals growth, where the nanoparticles nucleate and mature within the protein cages and cannot outgrow the cage size, and yields the nanocrystals of 5-8 nanometers $[1,61]$.

To ensure stability of specimens, minimize their thickness, and provide an adequate signal, additional characterization of MamC incubated with ferric chloride was performed with the protein prepared on a conventional EM grid. 


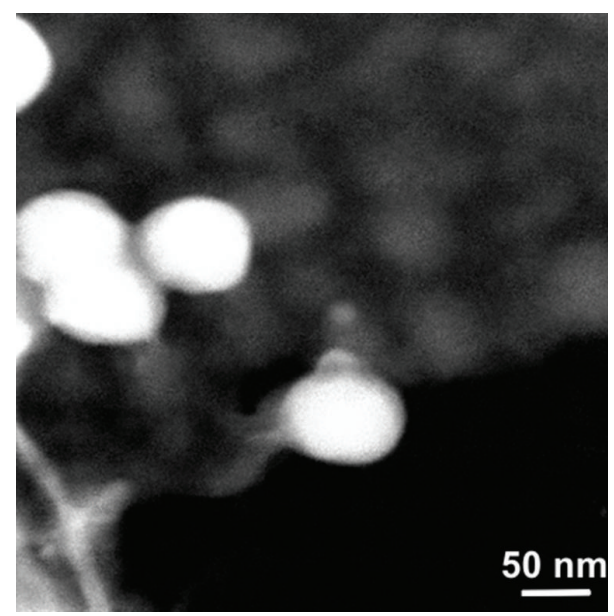

FIgURE 2: HAADF-STEM in situ characterization of MamC incubated with ferric chloride: (a) the iron-rich micelles are aggregating into larger hierarchical structures. The micelles in front are closer to the surface and appear in focus, whereas the micelles in the back, slightly out of focus, appear to be tightly packed.

Figures 3(a)-3(c) show elemental maps acquired in EFTEM mode for the zero loss region (a), Fe $\mathrm{L}_{2,3}$-edge (b), and $\mathrm{O} \mathrm{K}$ edge (c) energy loss values. EFTEM confirms the localized presence of oxygen and iron in MamC proteinaceous micelles incubated with ferric chloride. Since the iron energy loss is observed at higher energy levels compared to that of oxygen, the iron peaks are weaker; however, the elements are clearly distinguishable. The in situ HAADF (Figures 1 and 2) and EFTEM (Figure 3) images together provide strong evidence for the iron-binding ability of MamC micelles.

\section{Experimental Section}

3.1. Materials and Reagents. All aqueous solutions were prepared with deionized water passed through a Millipore MilliQ Plus water purification system $(\lambda=18.2 \mathrm{M} \Omega)$ and sparged with argon for $15 \mathrm{~min}$. (3-Aminopropyl)triethoxysilane (APTES, 99\%) and ferric chloride hexahydrate $\left(\mathrm{FeCl}_{3} \cdot 6 \mathrm{H}_{2} \mathrm{O}\right.$, $>99 \%$ ) were purchased from Sigma Aldrich and used without purification. The amount of protein in solution was maintained at $0.67 \mu \mathrm{M}$; MamC was incubated with $10 \mu \mathrm{M}$ ferric chloride solution prepared from the deoxygenated $0.5 \mathrm{M}$ stock solution.

Purified recombinant protein MamC from Magnetococcus marinus was obtained by cloning and expressing the gene $m m c 12265$ [31] into E. coli (TOP10) then disrupting the cells, and purifying the lysate following the protocol described by Valverde-Tercedor et al. [62], with the following modifications: (1) mmc1_2265 was amplified by polymerase chain reaction by using the following specific primers: fw3 ( $5^{\prime}$-ATGGCTGCCTTTAATTTGGCACTG-3') and rev2 ( $5^{\prime}$-TTACGGAGTTTCCAACTCCTGGGGATC-3'). (2) The expression conditions for the recombinant MamC protein by E. coli (TOP10) (TrcHisTOPO_ mmc1_2265) were $2 \mathrm{mM}$ of IPTG for 5 hours at $37^{\circ} \mathrm{C}$. (3) The purification was done using ÄKTA Prime Plus FPLC System (GE Healthcare) under denaturing conditions in a urea gradient. After elution of the protein, it was dialyzed overnight at $4^{\circ} \mathrm{C}$ against $1 \mathrm{~L}$ of Buffer 1 (20 mM phosphate buffer $\mathrm{pH} 8.0,4 \mathrm{M}$ urea, and $0.5 \mathrm{M} \mathrm{NaCl}$ ). To reduce the concentration of urea, the dialysis buffer was diluted stepwise 1:2 (four times) with Buffer 2 (50 mM Tris, $150 \mathrm{mM} \mathrm{NaCl}, \mathrm{pH}$ 8.5) and dialyzed for another 2-4 h after each dilution step. The isoelectric point for MamC $\left(I_{\text {ep }} 5.09\right)$ was calculated using the Expasy ProtParam tool [59].

Cloning and purification of the recombinant Mms6 from the M. Magneticum AMB-1 have been reported previously $[17,25,27]$. The Mms6 used in the study was dialyzed against $20 \mathrm{mM}$ TRIS, $100 \mathrm{mM} \mathrm{KCl}$, pH 7.45 buffer.

3.2. Specimen Preparation. To minimize the thickness of the liquid layer, the protein solutions were deposited onto plasma-cleaned TEM-transparent substrates, silicon nitride window membranes for the in situ imaging (Figures 1 and 2), and carbon-coated Au grids (QuantiFoil) for EFTEM imaging (Figure 3), using a Nano eNabler molecular printer (BioForce). Use of the Nano eNabler permitted the deposition of femtoliter volume droplets of liquid [63, 64]. Surface patterning tools (SPTs) with diameters of $10 \mu \mathrm{m}$ and $30 \mu \mathrm{m}$ were used for the specimen patterning. Prior to the liquid specimen loading, SPTs were treated with $\mathrm{UV} / \mathrm{O}_{3}$ plasma for $30 \mathrm{~min}$ to oxidize organic residues and form a thin layer of silicon oxide on the wall of channels and reservoirs, rendering them highly hydrophilic. Loading of the liquid specimen was performed immediately after the $\mathrm{UV} / \mathrm{O}_{3}$ plasma cleaning [64].

3.3. Functionalization of Silicon Nitride Windows. Silicon nitride windows membranes were cleaned by triple rinsing in toluene, then chemically pure acetone, and finally ethanol, followed by cleaning in $\mathrm{UV} / \mathrm{O}_{3}$ plasma for 45 minutes. Immediately after the plasma cleaning, the window membranes were functionalized with (3-aminopropyl)triethoxysilane (APTES), which is a covalent linker to facilitate protein immobilization on the surface $[65,66]$. To ensure protein integrity during the specimen deposition, silicon nitride windows were patterned on a custom-made cold stage at $7^{\circ} \mathrm{C}$.

3.4. Dynamic Light Scattering. Dynamic light scattering (DLS) and measurements of zeta potentials of the protein solutions were carried out with a Zetasizer Nanoparticle analyzer (Model: ZEN3690, Malvern Instrument Ltd., Southborough, MA). Prior to analysis, the buffer was filtered through a $0.2 \mu \mathrm{m}$ nitrocellulose membrane and the protein specimens were centrifuged for 20 minutes $\left(1000 \mathrm{rpm}, 23^{\circ} \mathrm{C}\right)$. The measurements were performed on numerous 10 -second acquisitions with 3 repeats. Data were processed by using Dispersion Technology Software 5.00 (Malvern Instrument Ltd.).

3.5. In Situ Fluid Cell Characterization. The iron-binding proteins were examined with a Continuous Flow Fluid Cell TEM Holder Platform (Hummingbird Scientific). After the patterning with the Nano eNabler, the windows were assembled and sealed in the liquid cell holder platform, resulting in the liquid specimen being sandwiched between the electrontransparent silicon nitride window membranes. Imaging and 


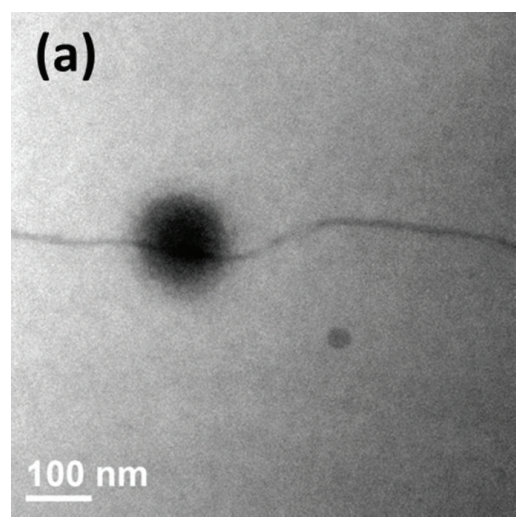

(a)

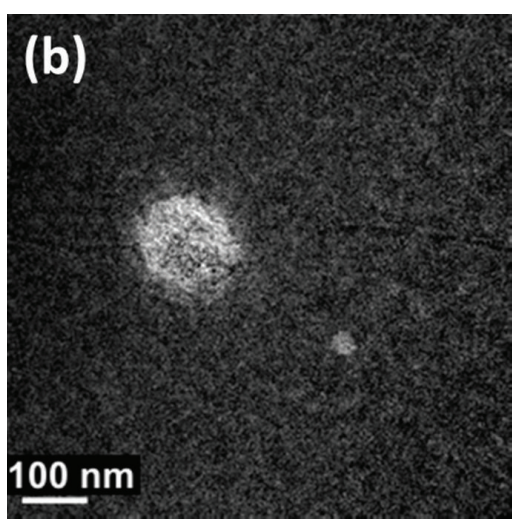

(b)

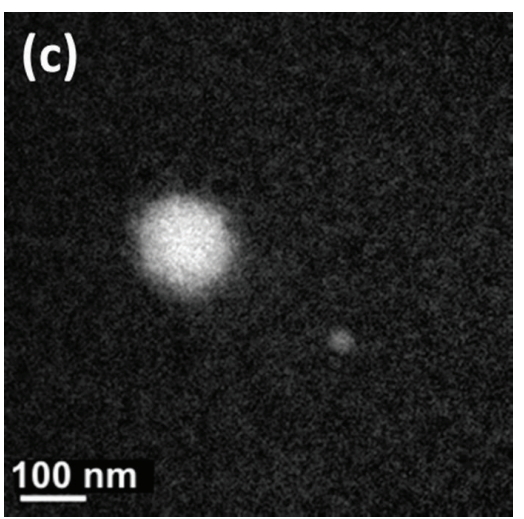

(c)

Figure 3: EFTEM images of MamC micelles prepared on a carbon grid. (a) Zero-loss image and elemental maps of (b) iron and (c) oxygen. Scale bar: $100 \mathrm{~nm}$.
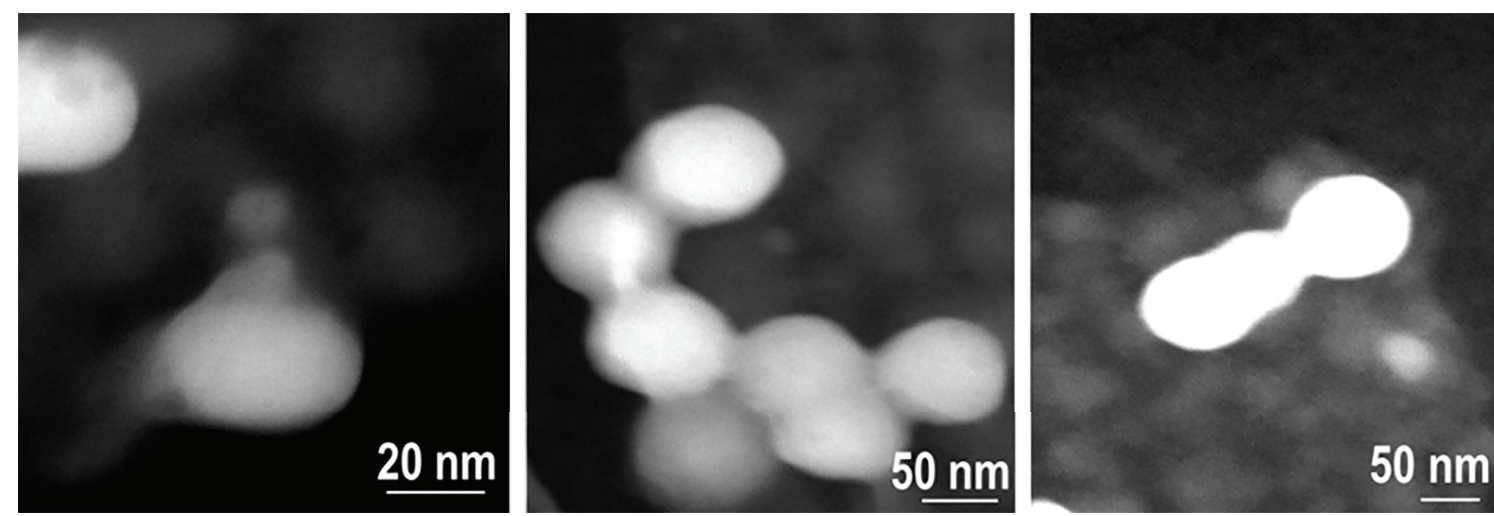

(a)

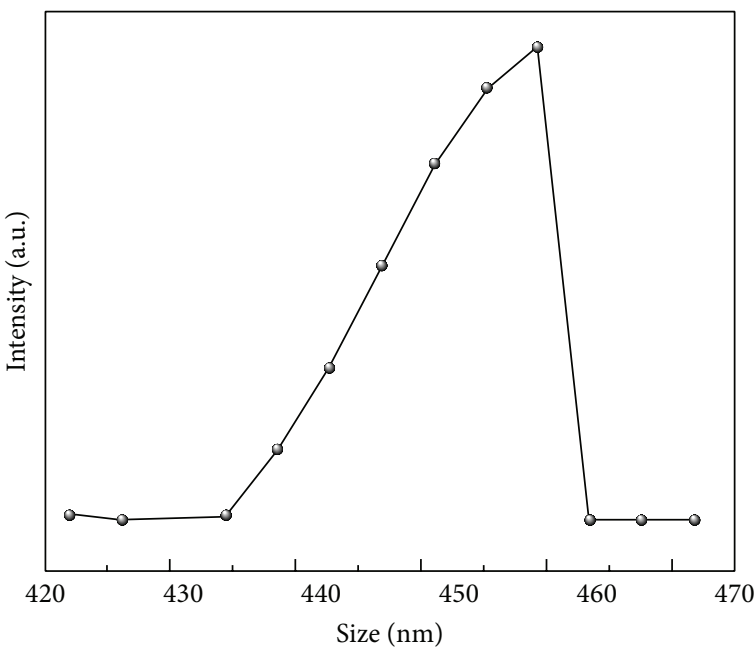

(b)

FiguRE 4: HAADF-STEM in-situ visualization of micellar aggregates in MamC incubated with ferric chloride overnight. The micelles in the back, slightly out of focus, appear to be tightly packed. (a) Representative images. Note the differences in the scale bars. Scale bar on the left: $20 \mathrm{~nm}$; scale bars in the middle and on the right: $50 \mathrm{~nm}$. (b) Intensity-based particle size distribution of micellar aggregates in MamC specimen incubated with iron overnight. 
characterization of the specimens were carried out with an FEI Tecnai $G^{2}$ F20 (S)TEM operating at an accelerating voltage of $200 \mathrm{kV}$ equipped with a Tridiem Gatan Imaging Filter (GIF), High Angle Annular Dark Field (HAADF), and energy dispersive X-ray spectroscopy (EDS) detectors. In situ fluid delivery was carried out with a syringe pump with the variable pumping speed $(2-5 \mu \mathrm{L} / \mathrm{min})$. For comparison, specimens were also printed on conventional EM grids and examined with a standard single-tilt holder. To ensure reproducibility of results, the sizes of micelles were determined from numerous HAADF images. Electron energy loss spectroscopy (EELS) was used to probe the localized chemical composition of the liquid specimens. EELS spectra and elemental maps were acquired in energy-filtered transmission electron microscopy (EFTEM) mode. Elemental maps of oxygen and iron were acquired with a slit width of $30 \mathrm{eV} \pm 1 \mathrm{eV}$. EELS spectra were acquired with a slit width of $10 \mathrm{eV}$ and dispersion of $0.5 \mathrm{eV} /$ pixel. Data analysis was performed with Digital Micrograph software (GMS version 2.11.1404.0) and OriginPro 9.0 software. To ensure reproducibility of results, micelle sizes were measured on micelles imaged in numerous micrographs obtained with the HAADF detector.

\section{Conclusions}

We have visualized micelles of MamC recombinant ironbinding protein in situ by utilizing the STEM-HAADF contrast enhancement of surface bound iron species. Further self-organization of iron-incubated MamC micelles produced iron-rich extended surfaces and points to enhanced iron binding. Our results represent a significant step forward in understanding the process of self-organization of ironbinding recombinant proteins employed in bioinspired synthesis of magnetic nanoparticles. Our findings are applicable for the in situ characterization of a variety of inorganicorganic interfaces in protein solutions.

\section{Conflict of Interests}

The authors declare that there is no conflict of interests regarding the publication of this paper.

\section{Acknowledgments}

This work was supported by the U.S. Department of Energy, Office of Science, Basic Energy Sciences, Materials Sciences and Engineering Division. The research was performed at the Ames Laboratory, which is operated for the U.S. Department of Energy by Iowa State University under Contract no. DE-AC02-07CH11358. MamC cloning and purification were done at the University of Granada, Spain. Concepción Jiménez López acknowledges the support from the Spanish Government through Grant CGL2010-18274 and the program Salvador de Madariaga. The authors thank the Laboratory of Professor Marit Nilsen-Hamilton for providing the recombinant biomineralization protein, Mms6.

\section{References}

[1] M. T. Klem, M. Young, and T. Douglas, "Biomimetic magnetic nanoparticles," Materials Today, vol. 8, no. 9, pp. 28-37, 2005.

[2] F. C. Meldrum, B. R. Heywood, and S. Mann, "Magnetoferritin: in vitro synthesis of a novel magnetic protein," Science, vol. 257, no. 5069, pp. 522-523, 1992.

[3] D. Resnick, K. Gilmore, Y. U. Idzerda, M. Klem, E. Smith, and T. Douglas, "Modeling of the magnetic behavior of $\gamma$ $\mathrm{Fe}_{2} \mathrm{O}_{3}$ nanoparticles mineralized in ferritin," Journal of Applied Physics, vol. 95, no. 11, pp. 7127-7129, 2004.

[4] I. Grunwald, K. Rischka, S. M. Kast, T. Scheibel, and H. Bargel, "Mimicking biopolymers on a molecular scale: nano(bio)technology based on engineered proteins," Philosophical Transactions of the Royal Society A: Mathematical, Physical and Engineering Sciences, vol. 367, no. 1894, pp. 1727-1747, 2009.

[5] J. J. de Yoreo and P. M. Dove, "Shaping crystals with biomolecules," Science, vol. 306, no. 5700, pp. 1301-1302, 2004.

[6] S. Foerster, "Amphiphilic block copolymers for templating applications," in Colloid Chemistry I, vol. 226 of Topics in Current Chemistry, pp. 1-28, Springer, Berlin, Germany, 2003.

[7] D. E. Morse, M. M. Murr, B. Schwenzer, J. R. Gomm, and R. L. Brutchey, "Silicatein proteins reveal unique mechanisms of hierarchical self-assembly and catalytic nanofabrication, leading to a new, generic, low-temperature method for catalytic nanofabrication," in Proceedings of the 233rd ACS National Meeting, vol. 96, p. 1, 2007.

[8] C. Nardin and W. Meier, "Hybrid materials from amphiphilic block copolymers and membrane proteins," Reviews in Molecular Biotechnology, vol. 90, no. 1, pp. 17-26, 2002.

[9] A. Wolff, K. Frese, M. Wissbrock et al., "Influence of the synthetic polypeptide c25-mms6 on cobalt ferrite nanoparticle formation," Journal of Nanoparticle Research, vol. 14, article 1161, 2012.

[10] D. W. P. M. Löwik, L. Ayres, J. M. Smeenk, and J. C. M. van Hest, "Synthesis of bio-inspired hybrid polymers using peptide synthesis and protein engineering," Advances in Polymer Science, vol. 202, no. 1, pp. 19-52, 2006.

[11] C. Tamerler and M. Sarikaya, "Molecular biomimetics: nanotechnology and bionanotechnology using genetically engineered peptides," Philosophical Transactions of the Royal Society A: Mathematical, Physical and Engineering Sciences, vol. 367, no. 1894, pp. 1705-1726, 2009.

[12] M. H. Nielsen, J. R. Lee, S. Aloni, and J. J. de Yoreo, in Proceedings of the 239th ACS National Meeting, San Francisco, Calif, USA, March 2010.

[13] Y. Amemiya, A. Arakaki, S. S. Staniland, T. Tanaka, and T. Matsunaga, "Controlled formation of magnetite crystal by partial oxidation of ferrous hydroxide in the presence of recombinant magnetotactic bacterial protein Mms6," Biomaterials, vol. 28, no. 35, pp. 5381-5389, 2007.

[14] A. Arakaki, M. Tanaka, and T. Matsunaga, in Proceedings of the International Chemical Congress of Pacific Basin Societies (Pacifichem '10), Honolulu, Hawaii, USA, December 2010.

[15] T. Prozorov, D. A. Bazylinski, S. K. Mallapragada, and R. Prozorov, "Novel magnetic nanomaterials inspired by magnetotactic bacteria: topical review," Materials Sciences and Engineering R: Reports, vol. 74, no. 5, pp. 133-172, 2013.

[16] T. Prozorov, S. K. Mallapragada, B. Narasimhan et al., "Proteinmediated synthesis of uniform superparamagnetic magnetite nanocrystals," Advanced Functional Materials, vol. 17, no. 6, pp. 951-957, 2007. 
[17] T. Prozorov, P. Palo, L. Wang et al., "Cobalt ferrite nanocrystals: out-performing magnetotactic bacteria," ACS Nano, vol. 1, no. 3, pp. 228-233, 2007.

[18] K.-I. Sano, K. Ajima, K. Iwahori et al., "Endowing a ferritinlike cage protein with high affinity and selectivity for certain inorganic materials," Small, vol. 1, no. 8-9, pp. 826-832, 2005.

[19] P. Tartaj, M. del Puerto Morales, S. Veintemillas-Verdaguer, T. González-Carreño, and C. J. Serna, "The preparation of magnetic nanoparticles for applications in biomedicine," Journal of Physics D: Applied Physics, vol. 36, no. 13, pp. R182-R197, 2003.

[20] Y. Y. Zheng, X. B. Wang, L. Shang et al., "Fabrication of shape controlled $\mathrm{Fe}_{3} \mathrm{O}_{4}$ nanostructure," Materials Characterization, vol. 61, no. 4, pp. 489-492, 2010.

[21] J. M. Galloway, A. Arakaki, F. Masuda, T. Tanaka, T. Matsunaga, and S. S. Staniland, "Magnetic bacterial protein Mms6 controls morphology, crystallinity and magnetism of cobalt-doped magnetite nanoparticles in vitro," Journal of Materials Chemistry, vol. 21, no. 39, pp. 15244-15254, 2011.

[22] J. M. Galloway, J. P. Bramble, A. E. Rawlings, G. Burnell, S. D. Evans, and S. S. Staniland, "Biotemplated magnetic nanoparticle arrays,” Small, vol. 8, no. 2, pp. 204-208, 2012.

[23] J. M. Galloway, J. P. Bramble, A. E. Rawlings, G. Burnell, S. D. Evans, and S. S. Staniland, "Nanomagnetic arrays formed with the biomineralization protein Mms6," Journal of Nano Research, vol. 17, pp. 127-146, 2012.

[24] A. Arakaki, J. Webb, and T. Matsunaga, "A novel protein tightly bound to bacterial magnetic particles in Magnetospirillum magneticum strain AMB-1," The Journal of Biological Chemistry, vol. 278, no. 10, pp. 8745-8750, 2003.

[25] T. Prozorov, S. K. Mallapragada, B. Narasimhan et al., "Proteinmediatedsynthesis of uniform superparamagnetic magnetite nanocrystals," Advanced Functional Materials, vol. 17, no. 6, pp. 951-957, 2007.

[26] L. Wang, T. Prozorov, P. E. Palo et al., "Self-assembly and biphasic iron-binding characteristics of Mms6, a bacterial protein that promotes the formation of superparamagnetic magnetite nanoparticles of uniform size and shape," Biomacromolecules, vol. 13, no. 1, pp. 98-105, 2012.

[27] S. Feng, L. Wang, P. Palo, X. Liu, S. K. Mallapragada, and M. Nilsen-Hamilton, "Integrated self-assembly of the Mms6 magnetosome protein to form an iron-responsive structure," International Journal of Molecular Sciences, vol. 14, no. 7, pp. 14594-14606, 2013.

[28] K. Grünberg, E. C. Mueller, A. Otto et al., "Biochemical and proteomic analysis of the magnetosome membrane in Magnetospirillum gryphiswaldense," Applied and Environmental Microbiology, vol. 70, no. 2, pp. 1040-1050, 2004.

[29] K. Grünberg, C. Wawer, B. M. Tebo, and D. Schüler, "A large gene cluster encoding several magnetosome proteins is conserved in different species of magnetotactic bacteria," Applied and Environmental Microbiology, vol. 67, no. 10, pp. 4573-4582, 2001.

[30] M. Tanaka, Y. Okamura, A. Arakaki, T. Tanaka, H. Takeyama, and T. Matsunaga, "Origin of magnetosome membrane: proteomic analysis of magnetosome membrane and comparison with cytoplasmic membrane," Proteomics, vol. 6, no. 19, pp. 5234-5247, 2006.

[31] S. Schübbe, T. J. Williams, G. Xie et al., "Complete genome sequence of the chemolithoautotrophic marine magnetotactic coccus strain MC-1," Applied and Environmental Microbiology, vol. 75, no. 14, pp. 4835-4852, 2009.
[32] A. Scheffel, A. Gärdes, K. Grünberg, G. Wanner, and D. Schüler, "The major magnetosome proteins MamGFDC are not essential for magnetite biomineralization in Magnetospirillum gryphiswaldense but regulate the size of magnetosome crystals," Journal of Bacteriology, vol. 190, no. 1, pp. 377-386, 2008.

[33] I. D. Campbell and B. Sheard, "Protein structure determination by NMR," Trends in Biotechnology, vol. 5, no. 11, pp. 302-306, 1987.

[34] A. Ilari and C. Savino, "Protein structure determination by Xray crystallography," in Bioinformatics, J. Keith, Ed., vol. 452 of Methods in Molecular Biology, pp. 63-87, Humana Press, 2008.

[35] J. S. Kim, T. LaGrange, B. W. Reed et al., "Imaging of transient structures using nanosecond in situ TEM," Science, vol. 321, no. 5895, pp. 1472-1475, 2008.

[36] R. Sharma, "Kinetic measurements from in situ TEM observations," Microscopy Research and Technique, vol. 72, no. 3, pp. 144-152, 2009.

[37] G. H. Campbell, T. B. LaGrange, W. E. King et al., "The HCP to BCC phase transformation in Ti characterized by nanosecond electron microscopy," in Proceedings of the International Conference on Solid-Solid Phase Transformations in Inorganic Materials, vol. 2, pp. 443-448, June 2005.

[38] X. D. Bai, Z. Xu, K. H. Liu, and E. G. Wang, "In situ TEM probing properties of individual one-dimensional nanostructures," International Journal of Nanotechnology, vol. 4, no. 1-2, pp. 119128, 2007.

[39] L. J. Chen, W. W. Wu, and C. H. Liu, "In situ ultrahigh vacuum transmission electron microscope investigations of dynamical changes of nanostructures on silicon," Advanced Science and Technology, vol. 46, pp. 111-119, 2006.

[40] M. Tanase and A. K. Petford-Long, "In situ TEM observation of magnetic materials," Microscopy Research and Technique, vol. 72, no. 3, pp. 187-196, 2009.

[41] H. Zheng, R. K. Smith, Y.-W. Jun, C. Kisielowski, U. Dahmen, and A. P. Alivisatos, "Observation of single colloidal platinum nanocrystal growth trajectories," Science, vol. 324, no. 5932, pp. 1309-1312, 2009.

[42] C. B. Murray, "Watching nanocrystals grow," Science, vol. 324, no. 5932, pp. 1276-1277, 2009.

[43] Z. H. Cao, P. Liu, X. K. Meng, S. C. Tang, and H. M. Lu, "In situ transmission electron microscopy observations of the crystallization of amorphous Ge films," Applied Physics A: Materials Science and Processing, vol. 94, no. 2, pp. 393-398, 2009.

[44] H. D. Espinosa, B. Peng, R. Agrawal, and R. A. Bernal, "In situ TEM experiments to assess the predictive capability of atomistic models," Microscopy and Microanalysis, vol. 16, pp. 1756-1757, 2010.

[45] D. H. Anjum, R. M. Stiger, J. J. Finley, and J. F. Conway, "Cryotransmission electron microscopy of Ag nanoparticles grown on an ionic liquid substrate," Journal of Materials Research, vol. 25, no. 7, pp. 1264-1271, 2010.

[46] J. M. Grogan and H. H. Bau, "The nanoaquarium: a platform for in situ transmission electron microscopy in liquid media," Journal of Microelectromechanical Systems, vol. 19, no. 4, pp. 885-894, 2010.

[47] J. E. Evans, I. Arslan, N. D. Browning et al., "Studying materials in-situ with the dynamic transmission electron microscope (DTEM)," Microscopy and Microanalysis, vol. 16, pp. 320-321, 2010. 
[48] G. H. Campbell, T. Lagrange, J. S. Kim, B. W. Reed, and N. D. Browning, "Quantifying transient states in materials with the dynamic transmission electron microscope," Journal of Electron Microscopy, vol. 59, no. 1, pp. S67-S74, 2010.

[49] G. Crivat and J. W. Taraska, "Imaging proteins inside cells with fluorescent tags," Trends in Biotechnology, vol. 30, no. 1, pp. 8-16, 2012.

[50] J. E. Evans, K. L. Jungjohann, P. C. K. Wong et al., "Visualizing macromolecular complexes with in situ liquid scanning transmission electron microscopy," Micron, vol. 43, no. 11, pp. 10851090, 2012.

[51] L. Zhang, J. Song, G. Cavigiolio et al., "Morphology and structure of lipoproteins revealed by an optimized negativestaining protocol of electron microscopy," Journal of Lipid Research, vol. 52, no. 1, pp. 175-184, 2011.

[52] B. Jachimska, M. Wasilewska, and Z. Adamczyk, "Characterization of globular protein solutions by dynamic light scattering, electrophoretic mobility, and viscosity measurements," Langmuir, vol. 24, no. 13, pp. 6867-6872, 2008.

[53] T. Uchihashi, N. Kodera, and T. Ando, "Guide to video recording of structure dynamics and dynamic processes of proteins by high-speed atomic force microscopy," Nature Protocols, vol. 7, pp. 1193-1206, 2012.

[54] C. Colliex, "Materials science: watching solution growth of nanoparticles in graphene cells," Science, vol. 335, no. 6077, pp. 44-45, 2012.

[55] K. L. Klein, I. M. Anderson, and N. de Jonge, "Transmission electron microscopy with a liquid flow cell," Journal of Microscopy, vol. 242, no. 2, pp. 117-123, 2011.

[56] E. A. Ring and N. de Jonge, "Microfluidic system for transmission electron microscopy," Microscopy and Microanalysis, vol. 16, no. 5, pp. 622-629, 2010.

[57] L. Wang, T. Prozorov, P. E. Palo et al., "Self-assembly and biphasic iron-binding characteristics of Mms6, a bacterial protein that promotes the formation of superparamagnetic magnetite nanoparticles of uniform size and shape," Biomacromolecules, vol. 13, no. 1, pp. 98-105, 2012.

[58] N. Ginet, R. Pardoux, G. Adryanczyk, D. Garcia, C. Brutesco, and D. Pignol, "Single-step production of a recyclable nanobiocatalyst for organophosphate pesticides biodegradation using functionalized bacterial magnetosomes," PLOS ONE, vol. 6, no. 6, Article ID e21442, 2011.

[59] C. Valverde-Tercedor, M. Montalbán-López, T. Trubitsyn et al., "Size control of in vitro synthetized magnetite crystals by MamC from Magnetococcus marinus MC-1," Biomaterials. In press.

[60] A. Wolff, N. Mill, K. Eckstadt et al., "Oriented attachment explains cobalt ferrite nanoparticle growth in bioinspired syntheses," Beilstein Journal of Nanotechnology, vol. 5, p. 210, 2014.

[61] T. Douglas and V. T. Stark, "Nanophase cobalt oxyhydroxide mineral synthesized within the protein cage of ferritin," Inorganic Chemistry, vol. 39, no. 8, pp. 1828-1830, 2000.

[62] C. Valverde-Tercedor, F. Abadía-Molina, M. Martinez-Bueno et al., "Subcellular localization of the magnetosome protein MamC in the marine magnetotactic bacterium Magnetococcus marinus strain MC-1 using immunoelectron microscopy," Archives of Microbiology. In press.

[63] J. Xu, M. Lynch, J. L. Huff et al., "Microfabricated quilltype surface patterning tools for the creation of biological micro/nano arrays," Biomedical Microdevices, vol. 6, no. 2, pp. 117-123, 2004.
[64] J. Xu, M. Lynch, S. Nettikadan, C. Mosher, S. Vegasandra, and E. Henderson, "Microfabricated "biomolecular ink cartridges"surface patterning tools (SPTs) for the printing of multiplexed biomolecular arrays," Sensors and Actuators B: Chemical, vol. 113, no. 2, pp. 1034-1041, 2006.

[65] K.-W. Huang, C.-W. Hsieh, H.-C. Kan et al., "Improved performance of aminopropylsilatrane over aminopropyltriethoxysilane as a linker for nanoparticle-based plasmon resonance sensors," Sensors and Actuators B: Chemical, vol. 163, no. 1, pp. 207-215, 2012.

[66] A. Huang, F. Liang, F. Steinbach, and J. Caro, "Preparation and separation properties of LTA membranes by using 3aminopropyltriethoxysilane as covalent linker," Journal of Membrane Science, vol. 350, no. 1-2, pp. 5-9, 2010. 

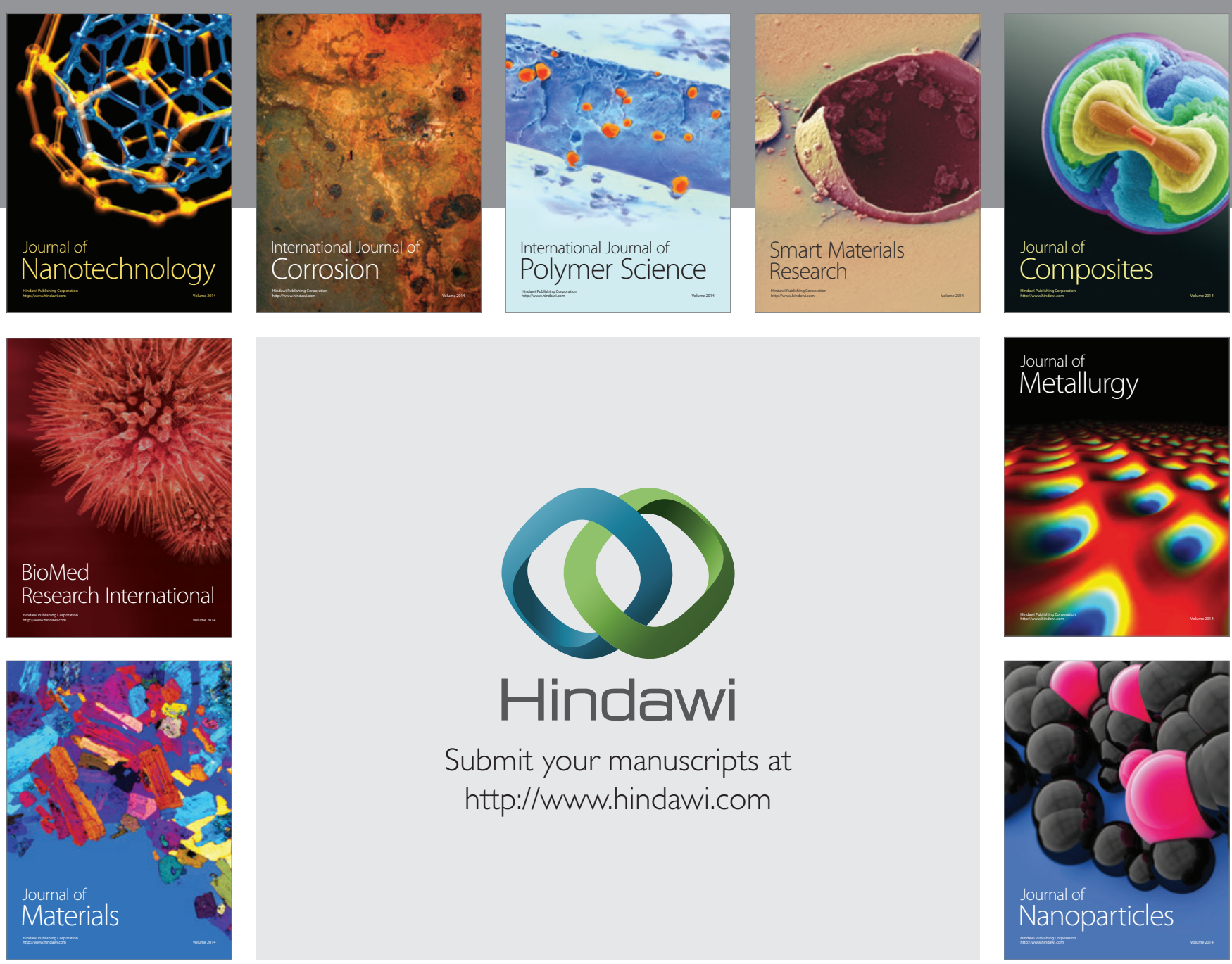

Submit your manuscripts at http://www.hindawi.com
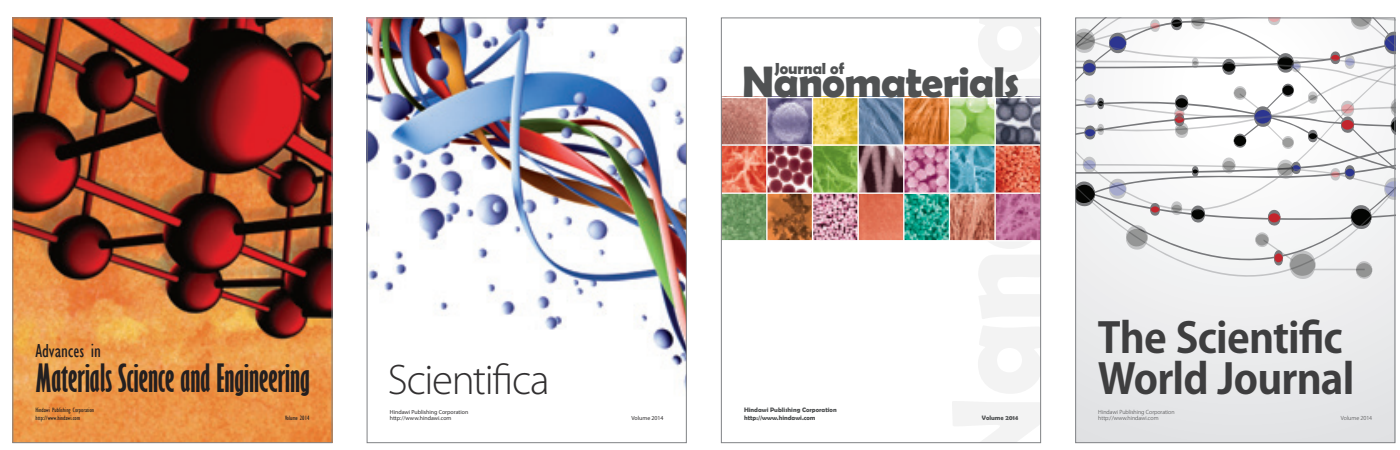

\section{The Scientific World Journal}
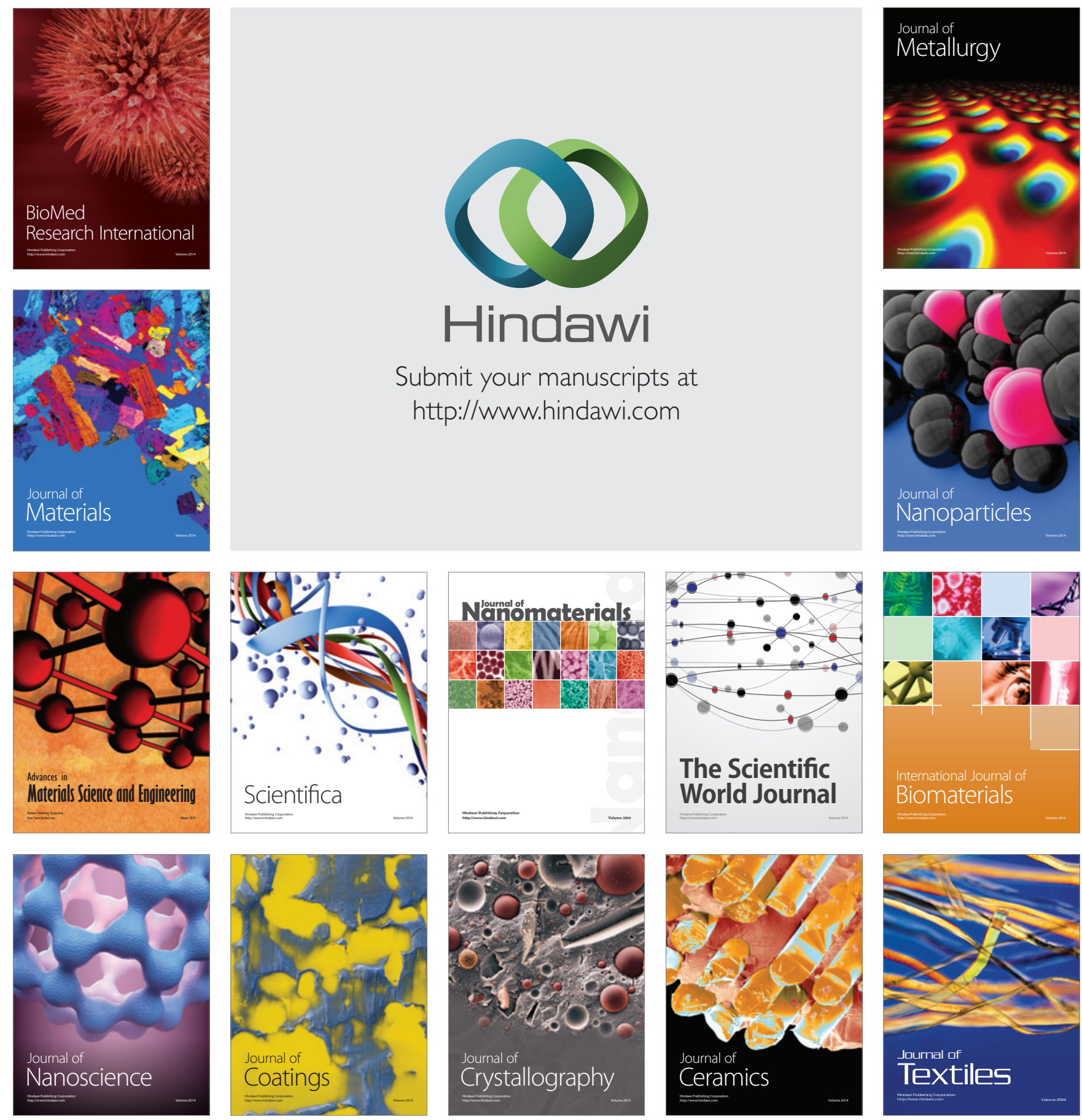